\title{
Establishing the minimal number of virtual reality simulator training sessions necessary to develop basic laparoscopic skills competence: evaluation of the learning curve
}

Ricardo Jordão Duarte, José Cury, Luis Carlos Neves Oliveira, Miguel Srougi

Sao Paulo University Medical School - CEPEC Vicky Safra - Department of Urology, Sao Paulo, Brazil

\section{ABSTRACT}

Introduction: Medical literature is scarce on information to define a basic skills training program for laparoscopic surgery (peg and transferring, cutting, clipping). The aim of this study was to determine the minimal number of simulator sessions of basic laparoscopic tasks necessary to elaborate an optimal virtual reality training curriculum.

Materials and Methods: Eleven medical students with no previous laparoscopic experience were spontaneously enrolled. They were submitted to simulator training sessions starting at level 1 (Immersion Lap VR, San Jose, CA), including sequentially camera handling, peg and transfer, clipping and cutting. Each student trained twice a week until 10 sessions were completed. The score indexes were registered and analyzed. The total of errors of the evaluation sequences (camera, peg and transfer, clipping and cutting) were computed and thereafter, they were correlated to the total of items evaluated in each step, resulting in a success percent ratio for each student for each set of each completed session. Thereafter, we computed the cumulative success rate in 10 sessions, obtaining an analysis of the learning process. By non-linear regression the learning curve was analyzed.

Results: By the non-linear regression method the learning curve was analyzed and a $\mathrm{r}^{2}=$ 0.73 ( $p<0.001$ ) was obtained, being necessary 4.26 ( five sessions) to reach the plateau of $80 \%$ of the estimated acquired knowledge, being that $100 \%$ of the students have reached this level of skills. From the fifth session till the 10th, the gain of knowledge was not significant, although some students reached $96 \%$ of the expected improvement.

Conclusions: This study revealed that after five simulator training sequential sessions the students' learning curve reaches a plateau. The forward sessions in the same difficult level do not promote any improvement in laparoscopic basic surgical skills, and the students should be introduced to a more difficult training tasks level.

\section{ARTICLE INFO}

\section{Key words:}

Laparoscopy; Teaching;

Aptitude; methods

[Subheading]; General Surgery

Int Braz J Urol. 2013; 39: 712-9

Submitted for publication:

July 17, 2012

Accepted after revision:

May 29, 2013

\section{INTRODUCTION}

Since 1991, when the first laparoscopic nephrectomy was performed, until our days, a substantial number of laparoscopic procedures became the gold standard in urologic surgery. However, to the surgeon become able to perform these techniques, a training period of time is necessary to ameliorate their skills: the learning curve. This learning curve is defined as the number of times a procedure must to be repeated in order to reach a plateau of excellence and high quality expertise (1). 
During the training period the new surgeons need to repeat the surgical procedures as many times as necessary to obtain the ability with the instruments. Actually, the challenge is to make this skills development period the most effective as possible.

Many reports have demonstrated that a high quality laparoscopic training program must include theoretical and practical activities, including manual and virtual simulators ("dry lab") and in animals ("wet lab"), before starting operating human subjects $(2,3)$.

Simulator training is well recognized to be a fundamental tool in laparoscopy learning process. However, the evaluation of the trainee's competence achievement and the ability to perform laparoscopic surgery in human beings and how to validate the training programs for the many simulators available in our days are still missing (4-6). Medical literature is also scarce on information to define a basic skills training program for laparoscopic surgery (peg and transferring, cutting, clipping).

The aim of this study was to determine the minimal number of simulator sessions in basic laparoscopic skills necessary to elaborate an optimal Virtual Reality training curriculum.

\section{MATERIALS AND METHODS}

Eleven fourth-year medical students with no previous experience in laparoscopy were spontaneously enrolled in the study. They were submitted to virtual reality simulator training sessions starting level (Immersion Lap VR, San Jose, CA) (Figure-1),

Figure 1 - The Virtual Simulator -Immersion Lap VR, San Jose, CA.

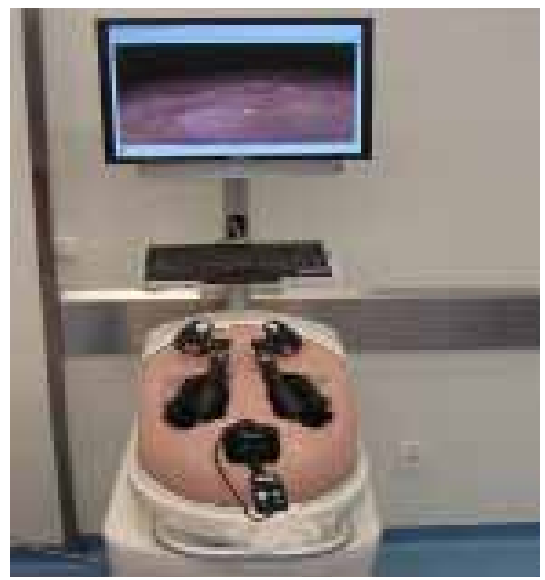

including the sequence of camera handling, peg and transfer, clipping and cutting (Figure-2). Each student trained twice a week until 10 sessions were completed. The score indexes were registered and analyzed (Table-1).

Figure 2 -The students were submitted to simulator training sessions starting at level 1 (Immersion Lap VR, San Jose, CA), including sequentially camera handling (a), peg and transfer (b), clipping (c) and cutting (d). Each student trained twice a week until 10 sessions were completed. The score indexes were registered and analyzed.
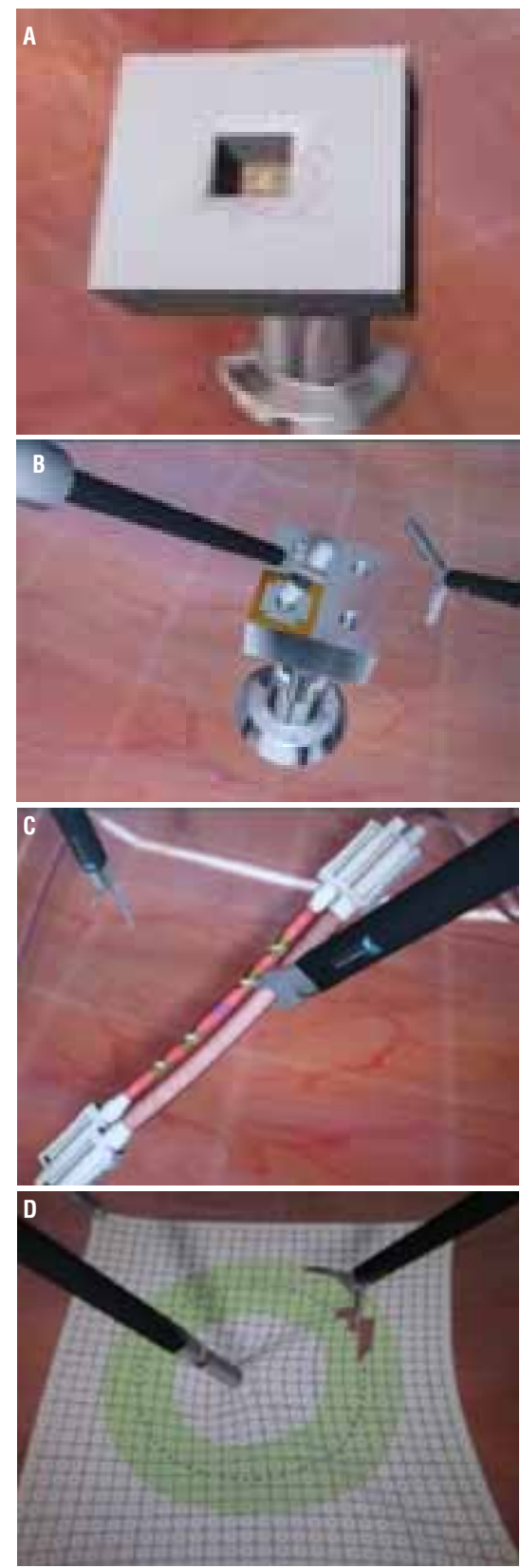
Table 1 (A.B.C.D) - List of basic procedures to be performed by the medical students: camera handling, peg and transfer, cutting and clipping. These procedures are in the simulator program.

\begin{tabular}{l} 
Camera handling \\
\hline Total time to complete task exceeded \\
Average time to find object exceeded \\
Task time limit exceeded \\
Total camera path length exceeded \\
Average camera path length exceeded \\
Average camera rotation exceeded \\
Percentage of time horizon maintained not completed \\
Maximum horizon degree deviation exceeded \\
Lens angle changes exceeded \\
Number of collisions exceeded \\
Found objects properly \\
Not found objects properly \\
Virtual assistance aid exceeded
\end{tabular}

Table 1A

\begin{tabular}{l} 
Peg and transfer \\
\hline Total time to complete task exceeded \\
Exceeded task time limit \\
Average time to complete left hand task exceeded \\
Average time to complete right hand task exceeded \\
All active pegs not placed in allotted time \\
Number of lost pins exceeded \\
Right hand to left hand ratio $\neq 1$ \\
Number of lost pins with left hand exceeded \\
Total number of dropped pegs exceeded \\
Number of dropped pegs with right hand exceeded \\
Number of dropped pegs with left hand exceeded \\
Number of broken pegs exceeded \\
Total number of next pegs exceeded \\
Left hand total path length exceeded \\
Right hand total path length exceeded \\
Left hand path length with peg exceeded \\
Right hand path length with peg exceeded \\
Left hand path length without peg exceeded \\
Right hand path length with peg exceeded \\
Virtual assistance needed
\end{tabular}

Table 1B 


\begin{tabular}{l}
\hline Cutting \\
\hline Exceeded task time limit \\
Lower than the max portion of cloth cut \\
More than the minimal portion of cloth cut \\
Complete pattern cut not completed \\
Did cloth come loose from clips? \\
Percentage cutting out of boundary area with right hand exceeded \\
Percentage cutting out of boundary area with left hand exceeded \\
Greatest distance out of cutting boundary with left hand exceeded \\
Greatest distance out of cutting boundary with right hand exceeded \\
Number of unsuccessful cutting attempts with left hand exceeded \\
Number of unsuccessful cutting attempts with right hand exceeded \\
Virtual aid usage
\end{tabular}

Table 1C

\begin{tabular}{|c|c|c|}
\hline Clipping & Yes & No \\
\hline \multicolumn{3}{|l|}{ Time to complete task exceeded } \\
\hline \multicolumn{3}{|l|}{ Total left hand path exceeded } \\
\hline \multicolumn{3}{|l|}{ Total right hand path exceeded } \\
\hline \multicolumn{3}{|l|}{ Blood loss } \\
\hline \multicolumn{3}{|l|}{ Dropped clips left hand exceeded } \\
\hline \multicolumn{3}{|l|}{ Dropped clips right hand exceeded } \\
\hline \multicolumn{3}{|l|}{ Vessel perforated? } \\
\hline \multicolumn{3}{|l|}{ Duct ligated or perforated? } \\
\hline \multicolumn{3}{|l|}{ Clips placed too close? } \\
\hline \multicolumn{3}{|l|}{ Maximum vessel stretch exceeded } \\
\hline \multicolumn{3}{|l|}{ Clips applied in marked areas } \\
\hline \multicolumn{3}{|l|}{ Correct number of clips placed in the marked area with left hand } \\
\hline \multicolumn{3}{|l|}{ Correct number of clips placed in the marked area with right hand } \\
\hline \multicolumn{3}{|l|}{ Misplaced clips left hand } \\
\hline \multicolumn{3}{|l|}{ Misplaced clips right hand } \\
\hline \multicolumn{3}{|l|}{ Cutting in the marked area } \\
\hline Virtual assistance needed & & \\
\hline
\end{tabular}

Table 1D 
Statistical analysis: Initially, the total of errors of the four evaluation sequences (camera, peg and transfer, clipping and cutting) were computed and thereafter, they were corrected by the total of items evaluated in each step, resulting in a percent ratio of success for each student for each set of each completed session (Friedman Repeated Measures test). Thereafter, we computed the number of cumulative successful tasks in 10 sessions, obtaining an estocastic analysis of the learning process (Dunnett's Method). By non-linear regression the learning curve was analyzed.

\section{RESULTS}

Median values and quartiles of the obtained scores were computed in each training session (Table-2). By the non-linear regression method the learning curve was analyzed and an $\mathrm{r} 2=0.73(\mathrm{p}<0.001)$ was obtained, being the double half-of-life $=4.26$ ( $\sim$ five sessions) to reach the plateau of $80 \%$ of the estimated acquired knowledge, since $100 \%$ of the students
Figure 3 - Learning curve revealing a plateau after the 5th training session on simulator.

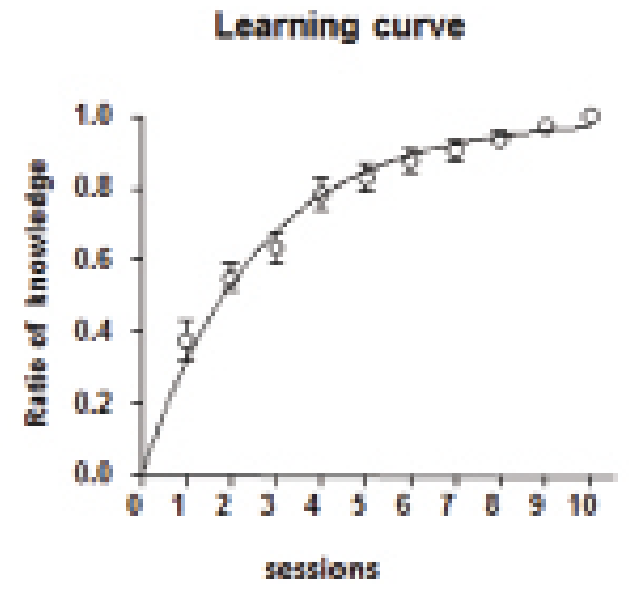

have reached this level of skill (Figure-3). From the fifth session till the 10th session, the gain of knowledge was not significant, although some students reached 96\% of the expected abilities (Table-3) (Figure-4).

Table 2 - Median scores and quartiles obtained by the group of students in each training session.

\begin{tabular}{lccccc}
\hline Training & N & Missing & Median & $25 \%$ & $75 \%$ \\
\hline Session-1 & 11 & 0 & 40,000 & 17,500 & 52,500 \\
Session 2 & 11 & 0 & 58,000 & 42,000 & 63,750 \\
Session 3 & 11 & 0 & 63,000 & 52,750 & 71,500 \\
Session 4 & 11 & 0 & 79,000 & 65,750 & 89,000 \\
Session 5 & 11 & 0 & 85,000 & 74,500 & 94,250 \\
Session 6 & 11 & 0 & 87,000 & 82,000 & 99,500 \\
Session 7 & 11 & 0 & 91,000 & 84,250 & 99,500 \\
Session 8 & 11 & 0 & 95,000 & 88,250 & 100,000 \\
Session 9 & 11 & 0 & 100,000 & 96,500 & 100,000 \\
Session 10 & 11 & 0 & 100,000 & 100,000 & 100,000 \\
\hline
\end{tabular}


Table 3 - To isolate the group or groups that differ from the others a multiple comparison versus control group procedure by Dunnett's method was performed revealing that after the fifth session no significant difference of score ranks was observed.

\begin{tabular}{lccc}
\hline Comparison & Diff of Ranks & $q^{\prime}$ & $P<0.05$ \\
\hline Session - 1 vs session - 10 & 95,000 & 6,107 & Yes \\
Session - 2 vs session - 10 & 76,000 & 4,885 & Yes \\
Session - 3 vs session - 10 & 69,000 & 4,435 & Yes \\
Session - 4 vs session - 10 & 50,500 & 3,246 & Yes \\
Session - 5 vs session - 10 & 41,500 & 2,668 & No \\
Session - 6 vs session - 10 & 29,000 & 1,864 & Do Not Test \\
Session - 7 vs session - 10 & 21,000 & 1,350 & Do Not Test \\
Session - 8 vs session - 10 & 17,000 & 1,093 & Do Not Test \\
Session - 9 vs session - 10 & 6,500 & 0,418 & Do Not Test \\
\hline
\end{tabular}

Figure 4 - Performance results of each student after 10 training sessions. All students reached the score of $80 \%$ of success, being $98 \%$ the maximum score value.

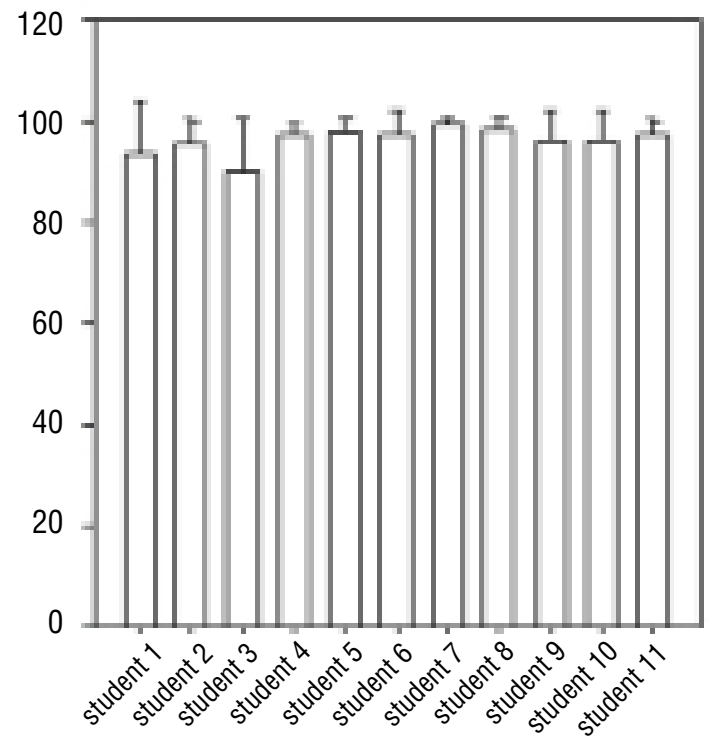

\section{DISCUSSION}

The capacitation of novice surgeons has evolved along the years. The advances of the minimally invasive techniques that the trainees should be exposed to, the ethical aspects of practicing surgery in human subjects and the shortening of the residence periods of training, have raised the need to elaborate a complete and compact learning program (7).

The employment of virtual simulators in these educational programs may be an useful tool for capacitation of these novices surgeons, avoiding the exposition of human patients to non-expert hands in initial phases of training. Furthermore, as long as the noninvasive techniques and devices get improved, the simulators are able to follow the innovations and to promote an updated training experience. They also allow the trainees to practice whenever they want $(8,9)$.

The educational institutions aim to elaborate a surgery learning program which includes virtual reality and animal models. With the shortening of training schedules, it is essential to spend this time in a wise and productive way (10).

Our goal was to define how many virtual reality training sessions were necessary to the medical students to reach a plateau in a specific task. The virtual simulators are able to analyze in a precise way the time spent to perform the tasks, economy of movements, skill, the path course and the intensity level of the task during the training sessions (8). 
Hogle et al. reported that after 7 to 8 training sessions the students did not reach the plateau level in navigation, coordination, grasping, peg, transfer, cut and clipping, with the Lap Sim device (11).

The learning curve can be defined as the graphic representation of the abilities acquired until a plateau of knowledge similar to the experts is reached (12).

Although simulation is a technique of reproducing a real situation with an improvement proposal, it is necessary to point out that the success on learning is more related to individual efforts than to an established number of sessions (13). Systematic reviews have shown that the performance of naive students in laparoscopy has better results in timing, precision and less errors after previous training (14-19).

After reaching the excellence level in a determined task, the trainee is able to move forward, to a more difficult level. Time to complete a task is also computed. So, when you elaborate a training program, it is more important to define a point of expertise to be reached than the number of hours of training (20). In this study we proposed ten training sessions, however 100\% of the students reached $80 \%$ of their capacitation after five times and it was considered the plateau of the learning curve. However, some of them reached a 96\% index of success, an indication that a small but continuous improvement of skills is still possible to be reached. Future studies should include more complexes tasks.

Despite the great number of studies on this subject, a consensus on a validated simulation system is still missing. An international consent must also be defined in order to uniform the training and assessment techniques (21). Recently, The European Endoscopic Surgery Consensus recommended that the basic laparoscopic surgical tasks should be practiced in a laboratory before the practice on human beings (22). But, although modern simulators are more realistic, it is still hard to transfer the virtual reality skills to surgical practice $(21,23,24)$. LapSim simulators have programs very similar to real surgery, and may be considered an advantageous factor. Van Hove et al. performed a review study on 104 published papers that focused on the progress of the students training on simulators and concluded that these equipments are able to assess the progress of the trainee on the simulators activities, but have no capacity to give credentials or evaluate their abilities as a laparoscopic surgeon (5).

We should consider that virtual simulation is a simple tool used to offer training and assessment in basic laparoscopy skills, in this target it can be useful, but getting abilities involve a complex issue. The costs of the VR system is a relevant disadvantage that has to be concerned when establishing a training center. Another issue to be pointed out is the question about the transferability of these skills into clinical practice, as well as the questionable ability of students or even surgeons to retain the skills once practice sessions are discontinued. The goal of this study was to establish the shortest training period with virtual reality simulator able to promote laparoscopic basic skills achievement to naïve students or even laparoscopy beginners.

In summary, although innovatory simulators are in continuous improvement, proficiency criteria, learning curves definition and validation of skills certification must be pursued by all those involved on laparoscopic training and medical education.

\section{CONCLUSIONS}

This study revealed that after five virtual reality simulator training sequential sessions the students' learning curve reaches a plateau. To stay in the same difficult level does not promote any improvement in basic laparoscopic surgery skills, and the students should be introduced to more difficult training tasks.

\section{CONFLICT OF INTEREST}

None declared.

\section{REFERENCES}

1. Laguna MP, de Reijke TM, Wijkstra H, de la Rosette: Training in laparoscopic urology. Curr Opin Urol. 2006; 16: 65-70.

2. Beyer L, Troyer JD, Mancini J, Bladou F, Berdah SV, Karsenty G: Impact of laparoscopy simulator training on the technical skills of future surgeons in the operating room: a prospectivestudy. Am J Surg. 2011; 202: 265-72. 
3. Snyder CW, Vandromme MJ, Tyra SL, Porterfield JR Jr, Clements RH, Hawn MT: Effects of virtual reality simulator training method and observational learning on surgical performance. World J Surg. 2011; 35: 245-52.

4. Greco EF, Regehr G, Okrainec A: Identifying and classifying problem areas in laparoscopic skills acquisition: can simulators help? Acad Med. 2010; 85: S5-8.

5. van Hove PD, Tuijthof GJ, Verdaasdonk EG, Stassen LP, Dankelman J: Objective assessment of technical surgical skills. $\mathrm{Br} \mathrm{J}$ Surg. 2010; 97: 972-87.

6. Imata N, Fujiwara M, Kodera Y, Tanaka C, Ohashi N, Nakayama $G$, et al.: Construct validity of the LapVR virtual-reality surgical simulator. Surg Endosc. 2011; 25: 423-8.

7. Botden SM, Jakimowicz JJ: What is going on in augmented reality simulation in laparoscopic surgery? Surg Endosc. 2009; 23: 1693-700.

8. Roberts KE, Bell RL, Duffy AJ: Evolution of surgical skills training. World J Gastroenterol. 2006; 12: 3219-24.

9. Fried GM, Feldman LS, Vassiliou MC, Fraser SA, Stanbridge D, Ghitulescu G, et al.: Proving the value of simulation in laparoscopic surgery. Ann Surg. 2004; 240: 518-25; discussion 525-8.

10. Torricelli FC, Guglielmetti G, Duarte RJ, Srougi M: Laparoscopic skill laboratory in urological surgery: tools and methods for resident training. Int Braz J Urol. 2011; 37: 108-11; discussion 112.

11. Hogle NJ, Briggs WM, Fowler DL: Documenting a learning curve and test-retest reliability of two tasks on a virtual reality training simulator in laparoscopicsurgery. J Surg Educ. 2007; 64: 424-30.

12. Argote L: Organizational learning: Creating, retaining and transferring knowledge. New York: Springer-Verlag, 1999.

13. Sweet RM, McDougall EM: Simulation and computer-animated devices: the new minimally invasive skills training paradigm. Urol Clin North Am. 2008; 35: 519-31.

14. Gurusamy KS, Aggarwal R, Palanivelu L, Davidson BR: Virtual reality training for surgical trainees in laparoscopic surgery. Cochrane Database Syst Rev. 2009; 1: CD006575.

15. Brunner WC, Korndorffer JR Jr, Sierra R, Massarweh NN, Dunne $\mathrm{JB}$, Yau CL, et al.: Laparoscopic virtual reality training: are 30 repetitions enough? J Surg Res. 2004; 122: 150-6.
16. Aggarwal R, Ward J, Balasundaram I, Sains P, Athanasiou T, Darzi A: Proving the effectiveness of virtual reality simulation for training in laparoscopic surgery. Ann Surg. 2007; 246: 771-9.

17. Ahlberg G, Enochsson L, Gallagher AG, Hedman L, Hogman C, McClusky DA 3rd, et al.: Proficiency-based virtual reality training significantly reduces the error rate for residents during their first 10 laparoscopiccholecystectomies. Am J Surg. 2007; 193: 797-804.

18. Cosman PH, Hugh TJ, Shearer CJ, Merrett ND, Biankin AV, Cartmill JA: Skills acquired on virtual reality laparoscopic simulators transfer into the operating room in a blinded, randomised, controlled trial. Stud Health Technol Inform. 2007; 125: 76-81.

19. Verdaasdonk EG, Dankelman J, Lange JF, Stassen LP: Transfer validity of laparoscopic knot-tying training on a VR simulator to a realistic environment: a randomized controlledtrial. Surg Endosc. 2008; 22: 1636-42.

20. Ahmed K, Jawad M, Abboudi M, Gavazzi A, Darzi A, Athanasiou $T$, et al.: Effectiveness of procedural simulation in urology: a systematic review. J Urol. 2011; 186: 26-34.

21. Wijn RP, Persoon MC, Schout BM, Martens EJ, Scherpbier AJ, Hendrikx AJ: Virtual reality laparoscopic nephrectomy simulator is lacking in construct validity. J Endourol. 2010; 24: 117-22.

22. van Dongen KW, Ahlberg G, Bonavina L, Carter FJ, Grantcharov $T P$, Hyltander A, et al.: European consensus on a competencybased virtual reality training program for basic endoscopic surgical psychomotor skills. Surg Endosc. 2011; 25: 166-71.

23. Ahmed K, Jawad M, Dasgupta P, Darzi A, Athanasiou T, Khan MS: Assessment and maintenance of competence in urology. Nat Rev Urol. 2010; 7: 403-13.

24. Fairhurst K, Strickland A, Maddern G: The LapSim virtual reality simulator: promising but not yet proven. Surg Endosc. 2011; 25: 343-55.

Correspondence address: Dr. Ricardo Jordão Duarte Rua Afonso Brás 525 / 82 Sao Paulo, SP,04510-011, Brazil Fax: +55 11 3842-6268 E-mail: ricjordao@uol.com.br 